\title{
El ejercicio de la traducción como acto del pensar. Entrevista a Antonio Gómez Ramos*
}

\author{
The exercise of translation as an act of thinking \\ Interview with Antonio Gómez Ramos \\ O exercício da tradução como um ato do pensar. \\ Entrevista a Antonio Gómez Ramos
}

Pablo C. Pulgar Moya**

\section{Introducción}

Esta entrevista tuvo lugar el día 25 de julio de 2019 en el café de la céntrica librería Dussmann, en Berlín, después de un encuentro en la Biblioteca Jacob-und-Wilhelm-Grimm-Zentrum de la Humbodlt Universität zu Berlin. Aprovechando la presencia del profesor Antonio

\footnotetext{
* Antonio Gómez Ramos es profesor titular de filosofía en la Universidad Carlos III de Madrid. Doctor en Filosofía por la Universidad Autónoma de Madrid, estudió filosofía y Germanística en Madrid y en Berlín. Su investigación se centra la teoría crítica, la hermenéutica y la teoría de la interpretación, especialmente referida a problemas de traducción y de comprensión intercultural. Se ocupa además del problema de la historicidad y de la comprensión del tiempo histórico y del pasado como memoria. Ha publicado, editado y traducido numerosos textos y artículos especializados. Ha traducido obras de Gadamer, Koselleck, Dilthey y Jameson, es reconocido además por su excelente traducción de la Fenomenología del Espíritu de Hegel (2010). Es autor de Entre las líneas. Gadamer y la pertinencia de traducir (2000); Reivindicación del centauro. Actualidad de la filosofía de la historia (2004); Sí mismo como nadie. Para una filosofía de la subjetividad (2015), y Las razones de la amargura. Variaciones sobre el resentimiento, el perdón y la reconciliación (2018), junto a Carlos Thiebaut.

** Chileno. Doctor en Filosofía por la Ruprecht-Karls-Universität Heidelberg. Profesor y Licenciado en Filosofía por la Pontificia Universidad Católica de Valparaíso. Profesor Adjunto en el Instituto de Filosofía, Universidad Católica Silva Henríquez. Contacto: pablo.pulgar.m@hotmail.com
}

ORCID: https://orcid.org/0000-0002-9594-2070 
Gómez-Ramos en Berlín, a causa de su pasantía de investigación en esa ciudad, se realizó la siguiente conversación.

Pablo Pulgar Moya: Para dar comienzo a esta conversación, quería preguntarte por el acto de la traducción filosófica y, con ello, por el valor del trabajo traductológico en cuanto tal, a saber, ¿en qué medida esta labor se transforma en una actividad, primero, hermenéutica, y, segundo, ¿qué problemas se encuentran al llevar a cabo esta empresa?

Antonio Gómez Ramos: En mis comienzos, a la vez que traducía a Gadamer, yo estuve trabajando con la hermenéutica, explorando la idea de que la traducción es una actividad filosófica. Filosofar, pensar, es traducir, la historia de la filosofía es una historia de la traducción desde los griegos, pasando por el latín. Los filósofos están siempre trabajando en muchas lenguas a la vez, siempre escribiendo y leyendo en alemán, inglés, francés, español, griego o latín, de modo que filosofar y traducir son cosas que van siempre juntas, a pesar de lo cual históricamente la filosofía se ha ocupado muy poco de la traducción, si bien recientemente hay una cosa que se llama "traductología", pero es más bien una ciencia de cómo traducir, una técnica. En cambio, una filosofía de la traducción, bueno, hay cosas en el siglo XX, sobre todo en el mundo francés, algunas en el mundo alemán, que están más cerca de la hermenéutica, cerca de la deconstrucción del lenguaje. Derrida escribió cosas muy interesantes acerca de la traducción, me refiero ya a textos largos; porque frases acerca de la traducción tienen todos los filósofos, el mismo Heidegger. La verdad es que yo siempre he pensado que hacer filosofía va ligado con traducir. La filosofía es lenguaje y es reflexión sobre el decir de las cosas, pero finalmente hay un problema con el lenguaje mismo. Si uno es muy platónico, muy idealista en el peor sentido, quizás puede imaginar un pensamiento muy universal, independiente del cuerpo de las lenguas, pero si el pensamiento tiene que darse siempre en una lengua histórica material, como desde luego es el caso, entonces sí que hay un problema de la traducción en el seno de la filosofía.

P.P.M: Planteando esta misma problemática de la traducción, crees que la pérdida que comporte trasladar un término de una lengua a otra, finalmente se transforma más en una empresa de interpretación, ¿cómo lo ves? 
A.G.R: Siempre hay una pérdida, pero, por otro lado, además de una pérdida, o más aún que eso, traducir es un acto natural del lenguaje, del pensamiento; no puede no darse. Siempre en la traducción estamos perdiendo, aunque a veces se gana. Sí, es verdad que se ven las cosas de otro modo. Esto ocurre mejor en la literatura; en filosofía es más difícil decir que una obra original mejore en una traducción. Muchas veces los poemas suenan mejor en otro idioma que en el original. En filosofía no, pero sí es verdad que la traducción en filosofía determina el modo en que se va a pensar a continuación. El modo en que Boecio tradujo a Aristóteles al latín determinó el pensamiento medieval y, por esa vía, el moderno. Heidegger lo recordaba, con cierto tono acusatorio. De manera que siempre hay pérdidas respecto del original; otra cosa es qué sea un original, si es que hay un original realmente. Y no lo hay. Hermenéuticamente, sabemos que no hay un original prístino y esencial. Un texto es un tejido de otros textos y lecturas anteriores. El original es también una convención. Por eso no hay que lamentarse con la pérdida, hay que saber que es algo con lo que jugamos.

P.P.M: Antes de empezar esta entrevista platicábamos sobre Hegel. Demos un giro justamente hacia Hegel, considerando que eres traductor de la Fenomenología del Espíritu ${ }^{1}$. Bosquejado, en que podrías centrar la importancia de una vuelta, de un retorno a este texto que, por cierto, es el escrito que se ha forjado mayor fama entre los hegelianos del siglo XX.

A.G.R: Desde luego es una vuelta al texto. Podríamos mirarlo con la idea de Benjamin: uno tiene una deuda para con el texto y una forma de saldar esa deuda es traduciéndolo. O podríamos decir también, y esto es muy de la hermenéutica, muy de Gadamer, que un texto existe $\mathrm{y}$ vive en sus lecturas, en sus interpretaciones y en sus traducciones. Una traducción forma parte de la historia del texto, y un texto no es distinto de su historia. Ocurre, además, que mientras los textos clásicos

1 Publicada en 2010 por la editorial Abada, en una edición bilingüe y realizada sobre la base de la edición histórico-crítica de Bonsiepen y Heede, publicada ésta en 1980 (Hamburgo: Felix Meiner) como vol. 9 de las Gesammelte Werke, junto a un acabado y extenso aparato de notas a pie de página que nos advierten de variantes en las diferentes ediciones, así como de ripios en la traducción, polisemias y juegos de palabras que, en español, suelen pasar inadvertidas. Además de ello, esta edición viene acompañada de un extenso glosario terminológico alemán/español, un índice triple de nombres citados por Hegel y notas explicativas a final de texto. 
acaban, por así decirlo, por ser eternos, intemporales, las traducciones son efímeras. Eso ya lo vio Benjamin, que decía muy bellamente que la traducción toca al original como la tangente al círculo. La toca en un punto, pero no llega realmente al núcleo y por eso las traducciones no viven más allá de unos decenios. Sobre todo con los clásicos, hay que volverlos a traducir, volverlos a leer. Y con Hegel especialmente, a Hegel se lo está volviendo a leer, se lo está volviendo a entender. Este texto en concreto, la Fenomenología del Espíritu, que por alguna razón es el texto más fascinante de Hegel, también se alza como uno de los más fascinantes de la historia de la filosofía, uno de los más bonitos. Siempre habría que volver a traducirlo. En casi todas las lenguas hay varias traducciones. En español había, hasta los años 60 , solamente una y ahora, pues bien, hay cuatro, y seguirá habiendo más, todo esto forma parte de la historia del texto: sus traducciones y la obligación de traducirlo.

P.P.M: Claro, en los últimos años han aparecido sucesivas traducciones de la Fenomenología del Espíritu, como es el caso de la italiana de Garelli, o la francesa de Jean-Pierre Lefebvre.

A.G.R: Todo el pensamiento francés estuvo determinado por la traducción de Hyppolite, que, a su vez, está determinada por la lectura de Kojéve y es una traducción que se ha quedado, hasta cierto punto, anticuada. Se da además la circunstancia de que Hyppolite no hablaba alemán, solo lo leía, excelentemente eso sí, pero lo hablaba mal. Algo así puede marcar mucho la traducción. Ahora hay tres versiones más nuevas al francés, cada una diferente. Se trata siempre de la historia del texto.

P.P.M: ¿Crees que es una tarea filosófica vital una vuelta por los diversos estadios de la Fenomenología hegeliana para entender una teoría general de la subjetividad o referida a la subjetividad? Ya como traductor, ya como lector de Hegel.

A.G.R: El traductor es un ser más bien humilde, está al servicio del texto. Se supone que entiende el texto que traduce. El traductor también tiene que ponerle un límite a su comprensión, en el sentido que Schleiermacher decía, que la tarea de comprender es tratar de entender al autor mejor de lo que él se comprendía a sí mismo. Pero al traducir la cuestión es que, incluso comprendiendo más, o supuestamente 
comprendiendo más, no puedes, como traductor, poner más de lo que en el original ponía, aunque tal vez puedas dejar traslucir más, de alguna manera. Como lector de Hegel, como lector interesado que soy yo en Hegel, pienso que Hegel es fundamental a la hora de comprender la subjetividad moderna, la de un sujeto que se concibe a si mismo viéndose como histórico y mirándose en su historia. Y que además es la historia del espíritu humano, de la subjetividad, quien lo piensa como un sujeto libre que se piensa a sí mismo, que se construye a sí mismo como histórico, mirando su propia historia. Es una lectura, pero trataría de separarla del fenómeno de la traducción.

P.P.M: Se me viene a la cabeza el mismo Hegel, por ejemplo, traduciendo él a Aristóteles.

A.G.R: Efectivamente. O, incluso, muchos de los conceptos más complicados de la Fenomenología, el famoso "an sich" que unos, también yo, traducen como "en si". Hay quienes protestan porque "en si" en castellano no significa nada. "An sich", por un lado, era una expresión muy suaba, muy del dialecto de Hegel; pero, por otro, "an sich"era

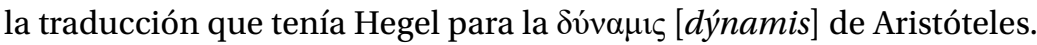
Así que se lo podría traducir como "en potencia". Ya incluso ese término tan original, que está en el núcleo mismo de la obra, resulta que traduce una historia anterior y que además es fundamental para comprender a Hegel.

P.P.M: A propósito de esto, vienen a mi mente los pequeños pasajes de la traducción de Zubiri de la Fenomenología, por ejemplo, la cual es bastante interpretativa. Justamente ahí se ve la plasticidad que puede llegar a tener una traducción. Siguiendo con Hegel, ¿Crees que en Hegel haya una relación directa entre su esfuerzo fenomenológico, contenido en la Fenomenología del espíritu fundamentalmente, y el lenguaje como tal? Es decir, ¿hasta qué punto el lenguaje se concibe como un medio articulador de las categorías de la subjetividad?

A.G.R: Te voy a responder primero como traductor, después, si quieres, vamos como intérprete. Indudablemente los dos se tendrían que fundir al final. Para empezar con el lenguaje de Hegel, ahí qué pasa. Pasa que el lenguaje de Hegel tiene una ventaja y un inconveniente. Es un buen escritor, a menudo muy brillante, a pesar de su oscuridad. Ser un buen escritor no es frecuente entre los filósofos alemanes. No lo 
era Kant, por ejemplo. Además, Hegel es muy fenomenológico cuando dice que hay que atender a la cosa misma, dejar que la cosa misma haga, ¿no? Él también deja que el lenguaje mismo haga, esto es, que hable. Hegel no comete ninguna violencia con el lenguaje, a diferencia de muchos filósofos. Hegel no usa jergas. No inventa términos técnicos, a diferencia de Kant, quien sí lo intentaba con distinciones como la de trascendental, trascendente. La filosofía muchas veces intenta encorsetar la realidad dentro de términos técnicos que supuestamente definen o se refieren exactamente a la cosa. Y Hegel, en cambio, sabe que el lenguaje ha validado a la filosofía, que el lenguaje tiene su propia vida. Escribe, además, cuando el alemán está formándose como lengua filosófica. Hacía solo cincuenta años que existía el alemán como lengua filosófica y Hegel era consciente de eso. Un poquito antes de la Fenomenología escribió una carta diciendo "hay que hacer que el alemán aprenda a hablar filosofía". Entonces él sabe que el alemán tiene que aprender a hablar de manera filosófica, pero que la forma en que la filosofía se hace lenguaje es dejar que el lenguaje natural, el lenguaje que habla la gente, exprima y explote todas sus potencialidades, todos sus matices. Realmente eso es lo que hace él. Juega mucho con dobles sentidos, con los sentidos intrínsecos, ocultos de las palabras. Deja hablar al lenguaje natural, vivo. Y aquí el pensamiento discurre en el lenguaje mismo. Los niveles y cambios del lenguaje, todos los matices, todos los armónicos que hay en una palabra están en el pensamiento de Hegel. Él va pensando con las palabras. Por la época escribía en algún ensayo que "hacer filosofía es saber lo que se dice, es ser consciente de la palabra que se usa". Solamente con pensar en las palabras que estamos usando ya estamos haciendo filosofía realmente. Y eso está en Hegel claramente.

En cuanto intérprete, me preguntabas por la teoría de la subjetividad. La subjetividad que aparece en el Hegel fenomenológico es la historia de la conciencia, la experiencia de la conciencia. Lo que le pase a la conciencia es lo que el texto irá diciendo de la conciencia misma. También con este doble nivel que tiene siempre la fenomenología, tan difícil de expresar. Lo que la conciencia vive y lo que la conciencia ve de sí misma, al final ya como un nosotros. Aquí sí hay un problema en Hegel, claramente, y es que nunca se sabe determinar desde qué punto habla el texto. Si habla desde el interior de la conciencia o si es el nosotros el que habla, si se está recopilando la experiencia de la conciencia, 
está viendo lo que es en sí, que la conciencia es nuestra área para sí. Hay dos niveles de lenguajes. Pero el juego de esos dos niveles es la subjetividad misma.

P.P.M: A propósito de tu respuesta, me acordaba que el concepto hegeliano finalmente también funciona como mediador, es el que articula el lenguaje. Es el lenguaje mismo.

A.G.R: Y por eso "concepto" no es un término. Término en el sentido determinado. Nunca es determinado un concepto que tiene que seguir formándose, que tiene su vida, la vida del concepto.

P.P.M: A propósito del lenguaje y siguiendo en esta línea, quería dar un pequeño salto. Teniendo en cuenta tu profuso conocimiento sobre el pensamiento de Gadamer, él decía justamente en "Acerca de la fenomenología del ritual y el lenguaje" que a la tradición fenomenológica le costaba traer a colación la reflexión acerca del lenguaje, que un problema típico de la tradición fenomenológica es no dar con el objeto. No tematizarlo. No había caso de que lo agarrara como tal. ¿Cuál crees que es la razón de este fenómeno? ¿Qué ha pasado que en esta tradición fenomenológica se les haya escapado el lenguaje? ¿Responde a modos históricos del tratamiento del tema?

A.G.R: Sí, ese uno de los ensayos más importantes de Gadamer, en sus últimos años. Con noventa años todavía era capaz de escribir un ensayo como ese. De todos modos, supongo que en Husserl, como de hecho también en Frege, había un cierto, vamos a decir, "platonismo" que le hacía abstraer no tanto del lenguaje como de las lenguas históricas -el francés, el inglés, el alemán, el italiano-, y eso es lo que se empieza a corregir, desde luego, con Heidegger. Heidegger es muy consciente ya de la importancia del lenguaje, y Gadamer sobre todo. Aunque el lenguaje entra solo en la tercera parte de Verdad y método, algunos críticos no ven claro que lo haga de modo consecuente con la historicidad de la comprensión que se expone en las partes previas del libro. En todo caso, lo que es muy importante desde el punto de vista traductológico es que, para Gadamer, el lenguaje solamente se da encarnado en palabras. De hecho, la imagen del lenguaje encarnado, actualizado en palabras, en actos de habla, al fin y al cabo, es lo que se replica en la metáfora teológica de la encarnación. Lo vio él en Agustín, en el que la voz interior solo se lee en palabras que históricamente se 
pronuncian en una determinada lengua. $\mathrm{Y}$ algo de esto sucede también en Hegel. Hegel, en el momento de la certeza sensible, al principio mismo de la fenomenología, llega a decir "el lenguaje es lo más verdadero", o lo más "de verdad": es así cuando la cosa misma se va a mostrar ostensiblemente: lo verdadero son las palabras que históricamente pronunciamos. Pero sí, es verdad que en la tradición fenomenológica de Husserl hay un descuido del lenguaje.

P.P.M: Cerrando la ronda de preguntas. Un tema que me interesa personalmente es la relación entre el acto ritual y el lenguaje. ¿Crees que, de cierta manera, este tipo de tematizaciones, el ritual, la palabra...? Los griegos desarrollaron diferentes formas para denominar la palabra. No sólo era $\lambda$ ó ${ }^{\circ}$ ○ [logos] sino era el $\mu \tilde{v} \theta$ os [mythos]. Me parece que en este caso Hegel se centra, sobre todo, en la teoría del logos y el mythos, que queda bastante anterior. En su obra la palabra "mythos" como tal aparece no más un puñado de veces como algo prefilosófico. Sin embargo, los mismos griegos, incluyendo a Aristóteles, tenían esta concepción que el mythos comportaba algo de verdad. De cierta manera, el ritual es la confirmación del mythos. Está conectado directamente con el lenguaje. Es algo que quiere confirmar el lenguaje.

A.G.R: El amigo del mythos es también el amigo de la sabiduría, decía Aristóteles. Si no recuerdo mal, en el texto de Gadamer al que te has referido, él pone el valor, le da todo su énfasis al ritual, a lo que tiene el lenguaje de ritual, de repetitivo. Del lenguaje de todos los días, del lenguaje convencional. Incluso si nos ponemos a hablar en heideggeriano del lenguaje impropio, no auténtico. El lenguaje siempre saluda por las mañanas. Se dice "buenos días", ¿̇no? En sí, eso no dice nada, pero si no dijéramos "buenos días", sin el rito de los "buenos días" no podríamos hablar luego ninguna otra cosa. Y Gadamer, a la vez que señala todo el valor del lenguaje ritual y que en su mayor parte el lenguaje es ritual y que con él se articula la comunidad de los hablantes, que es la comunidad del nosotros, señala también el valor del lenguaje no ritual. Justamente del lenguaje poético, cuando el lenguaje también es creativo. Produce entonces algo nuevo, cuando se separa del ritual, cuando rompe el ritual. Que, de nuevo, como en el caso de la existencia propia del de Heidegger, no es algo que deba ocurrir todos los días. Uno no puede ser un héroe todos los días, ni estar todos los días enfrentado a la angustia y a la verdad de la vida. No puede decir una poesía en cada pa- 
labra que dice. Ni siquiera podría pedir un café en la cafetería. Entonces, ahí están los dos polos. Todo el fundamento se produce históricamente en la repetición de rituales, la parte mítica del lenguaje, la parte mítica de lo que somos. Por eso también el lenguaje como creador, como ruptura, como momento de quiebra y de creación. Es esta fenomenología del ritual y del lenguaje. Y está la contraposición con Hegel y es que Hegel... yo no diría que Hegel desprecie el mito, en ningún caso. Él estaría de acuerdo con Aristóteles. Lo que pasa es que también sabe que en la sabiduría mítica hay una imagen olvidable. La filosofía tiene que despegarse, tiene que salir de sí. Y es el comienzo justamente del logos y de la filosofía, ¿no? Pero, en sí, implícitamente, en potencia, está ahí todo el logos ya, en el buen mito. La diferencia, como siempre, entre Hegel y Gadamer es que en Hegel veríamos una evolución histórica del mythos o de ese saber inocente, ingenuo, primero. Se extraña, se despliega, se hace mucho más múltiple, mucho más rico. Sabe mucho más de sí mismo. Hegel parece que tiende a contarnos eso en una narración histórico-dialéctica que para Gadamer sería más difícil de aceptar. Y, en todo caso, también en Hegel podría haber una autotransparencia final. El lenguaje ya lo sabe todo de sí mismo. Nuevamente es cómo leemos el saber absoluto: ¿puede todo el lenguaje hacerse concepto? Esa es una pregunta que deberíamos hacernos: si el concepto puede hacerse realmente autotransparente.

P.P.M: En este debate actual se llega a discutir una visión de sistema de Hegel, como un gran sistema cerrado, con la historia ya contenida y el concepto ya desarrollado y autotransparente. Hegel pensaba en el concepto como autotransparente. Nos damos cuenta en la Ciencia de la Lógica de la importancia del movimiento, porque no encontramos un momento en que realmente se quede inamovible. Y decir en el mismo movimiento acontece lo absoluto.

A.G.R: Salvo el momento en que ella, la Lógica, se ve a sí misma como movimiento, lo absoluto es el verse a sí mismo suelto de todo lo demás. No es solo el momento final, cuando se dice que "ya hemos llegado". Otra cosa es en la Fenomenología, porque no forma parte del sistema. Y luego la escalera hasta llegar al saber absoluto, que es una escalera de crecimiento, pero a la vez, como decíamos antes, cada uno de los escalones son los tropezones sucesivos de la conciencia. El juego paradójico de la Fenomenología es que cuanto más va cayendo la 
conciencia, cuanto más va tropezando, más va haciendo el ridículo; cuánto más se va deshaciendo, sin embargo más va creciendo y se va haciendo el espíritu. Es cómico, son situaciones cómicas, cada una de ellas, cada una de sus figuras. Pero luego, la acumulación de situaciones cómicas, escaladamente, al final produce el saber absoluto. Con lo cual no se trataría de un crecimiento por acumulación de la racionalidad, sino que todo lo contrario. Un vaciamiento sucesivo de las figuras de la conciencia. Cada una de ellas. El saber absoluto no es la culminación de la escalera. Es otra cosa. Pero ¿podemos pensar la historia, la historia humana, como algo así?

P.P.M: $i$ Tú crees que este vaciamiento del que hablabas se ve en la Fenomenología, se repite en la Lógica, se repite en la Filosofía del Derecho?

A.G.R: No tan directamente. No te lo sabría contestar de primeras. Desde luego, en la Fenomenología hay una estructura completamente distinta de las otras. Pero, por ejemplo, la Filosofía del Derecho sí que se da dentro de esa curiosa paradoja en Hegel. La desvalorización del individuo frente al Estado, que no hay por qué entender como un Estado en el sentido policíaco, del poder, sino de la eticidad. El individuo vale solo dentro de la eticidad; pero, a la vez, hay una especie de vaciamiento de sí, porque el individuo solo puede realizarse llenándose dentro de un esquema que le supera a uno. Se llena comprendiéndolo. De algún modo podrían buscarse paralelos. La Fenomenología es un libro muy raro, en cualquier caso. Por lo menos es narrativo. Encuentra en la narración una evolución, cosa que no ocurre en los otros. Hegel nunca supo qué hacer con ella, cómo encajarla en su sistema. Baste ver lo reducida que se queda en la Enciclopedia. Fue cambiando de sitio. Iba a ser una introducción al sistema, que era lo que se planteó y luego terminó afinando la Fenomenología del Espíritu.

P.P.M: Muy famosa es la discusión interpretativa del comienzo, del Ausgangspunkt, sea como obra autónoma o como la introducción y preámbulo al sistema de la ciencia.

A.G.R: Sí. Sobre eso los lectores de Hegel llevan mucho tiempo discutiendo. La Fenomenología, como obra literaria, como obra de creación de escritura, es un caso muy peculiar en la propia historia de la cultura humana. Lucien Lefebvre, su traductor francés, decía que es 
una de las grandes obras de la historia de la literatura, no sólo de la filosofía. Es una obra que Hegel escribió en muy poquito tiempo, y cambiándola sobre la marcha. Es un libro que escribió en un arrebato de inspiración durante un año y medio. Hegel llevaba años y años haciendo pruebas a ver si le salía el sistema. Los primeros esbozos del sistema (1803/04) de Jena, que después hemos ido conociendo. Y de pronto, en el momento más dramático de la historia, con Napoleón apoderándose de toda Europa, cuando llegó la batalla de Jena, Hegel llevaba allí ya un año y medio trabajando. Eran momentos de guerra, y eran momentos además muy complicados en lo personal. Estaba solo y había dejado embarazada a la casera, y el niño iba a nacer casi a la vez que el libro. Con la mujer encinta, sin dinero, sin perspectivas de trabajo, con el mundo deshaciéndose, y también la Universidad de Jena, que ya no era nada. Todos los famosos y todos sus amigos se habían ido. Y, en una especie de inspiración, Hegel sacó el libro a toda prisa. Además, modificando sobre la marcha la propia estructura del libro, según hemos sabido después. Cambiaba el índice, el título, etc. Todo ello escrito con notable inspiración literaria. Claramente las figuras que aparecen ahí, el lenguaje, las metáforas, son cosas que no vuelve a repetir después. Hay aquí algo de genial, de alguien completamente tomado por su propia idea, por su propio pensamiento sobre su obra, para producirlo con esa solidez. Por un lado, tan largo y tan oscuro, pero cuando se lee se ve que es tan coherente y tan compacto.

La Fenomenología, para empezar, tiene algo de fílmico. Los textos de Hegel, decía Adorno, son como películas; y es por eso, por la plasticidad de los conceptos. En la Fenomenología lo que aparece son figuras que se van haciendo, crecen, luego tropiezan y desaparecen. Van pasando cosas. A veces, más que distintas figuras, son variaciones de la misma forma. Son movimientos casi fílmicos, de una plasticidad enorme. También es así en la Lógica, seguramente, pero se ve mucho más en la Fenomenología. A veces, con cierta estructura casi escenográfica. En el caso del capítulo del amo y el esclavo, la lucha de las autoconciencias, tiene algo de mitológico. Las dos conciencias que se encuentran; ha habido montones de lecturas de ese capítulo. Dos que se encuentran como en el desierto, y tienen que luchar por el reconocimiento; es tremenda esa figura. O momentos directamente cómicos, luego más adelante, como en el ejemplo del caballero de la virtud, peleando esa 
pelea de esgrima frente al espejo contra lo que Hegel llama el curso del mundo: es una burla cruel de los moralistas. Cada uno de estos momentos tiene una fuerza dramática propia de un escenógrafo más que de un pensador. También Platón era un autor de teatro, ¿no? Y algo de eso tendría Hegel, sin duda.

P.P.M: Antonio, nuevamente muchas gracias por esta agradable conversación e intercambio de ideas.

A.G.R: De nada, muchas gracias a ti. Ha sido una entrevista y conversación muy agradable. 